\title{
Emission and Cost Configurations in Earthmoving Operations
}

DOI 10.5592/otmcj.2012.1.4 Research paper

\author{
Alireza S. Kaboli \\ School of Civil and Environmental \\ Engineering \\ The University of New South Wales \\ Sydney 2052 NSW Australia
}

\author{
David G. Carmichael \\ School of Civil and Environmental \\ Engineering \\ The University of New South Wales \\ Sydney 2052 NSW Australia \\ e-mail: D.Carmichael@unsw.edu.au
}

BRIEF INTRODUCTION TO THE PROBLEM. The paper examines the influence of varying operation parameters such as equipment heterogeneity, payload, and travel times, on unit emissions and unit costs in earthmoving and like operations. The need to minimise cost and maximise production of earthmoving and like operations has led to such operations being heavily scrutinised. With environmental issues becoming more important, there is now a need to additionally scrutinise and minimise emissions. Cycle times and production were measured in a cut-and-fill case study operation; average fuel burn data are converted to idling and nonidling emission fractions; and queuing theory is used for the theoretical evaluation of production for varying operation parameters. It is demonstrated that the optimum fleet sizes in terms of minimum unit costs and minimum unit emissions coincide in earthmoving operations. The result is independent of any specific operational parameters. The paper concludes that the traditional way of undertaking earthmoving operations, namely configuring to give minimum unit costs, will also result in minimum unit emissions. And that configuring differently to that will lead to unnecessary emissions. The result carries over to quarrying and surface mining operations.

Keywords

Earthmoving; Optimal cost and emissions;

Production; Quarrying; Surface mining

\section{Introduction}

Earthmoving operations typically involve a fleet of trucks cycling between an excavator/loader and dump points. The analysis to obtain the optimum fleet size based on minimum cost per production (unit costs) is well-established, whereas little attention has been paid to the minimum emissions per production (unit emissions) problem. Off-road vehicles are a significant source of air pollution and produce large volumes of emissions compared to on-road vehicles such as automobiles. For example, the amount of particulate matter from a bulldozer with a $175 \mathrm{hp}$ engine is nearly 500 times more than that of a new automobile (EPA, 2005). Reducing pollution from such off-road vehicles will provide decreased environmental problems. Because of the importance society places on this issue, effort is be- 
ing directed to estimating and containing the level of pollutants produced by earthmoving equipment. Government regulations, fuel specifications, engine modifications, and vehicle fleet management are some approaches adopted to decrease pollution (EPA, 2005).

The paper addresses the unit cost and unit emissions cases for both homogeneous fleets of trucks (all trucks the same) and heterogeneous fleets of trucks (trucks differ). Employing equipment that is the same makes it easier to manage an earthmoving operation; it is possible to adjust the capacity of buckets to maximise payloads, while a homogenous truck fleet will also reduce the truck bunching effect because cycle times are similar for trucks with the same payload and engine power. Homogeneous assumptions also facilitate earthmoving analyses (Carmichael et al., 2012; Ahn et al., 2009; Rekapalli, 2008). However, it is not always the case that homogeneity of equipment occurs in practice and an operation manager may have to use whatever equipment is available.

The heterogeneous case (production only) has been examined in some studies. Burt and Caccetta (2007) revisit the matching of equipment presented in Morgan and Peterson (1968). Gross and Ince (1981) convert a heterogeneous operation into an equivalent homogenous one, based on a weighted average of rates and times for service times and backcycle times. Carmichael (1990) uses these results to evaluate heterogeneity in deterministic finite source queues. Carmichael suggests expressions for server utilisations for two scenarios the 'no passing' and 'general' cases. As the term implies, overtaking of trucks is not permitted in the 'no passing' case and trucks are loaded in a strict order; this restraint is removed in the 'general' case and trucks are allowed to be loaded in any order. It is seen that all the existing research regarding heterogene- ity has been about cost and production. No attempt has been made to examine the influence of heterogeneity on emissions, as covered in this paper.

Confining itself to conventional excavator-truck earthmoving operations, this paper examines the effects of varying operation parameters, including heterogeneity, payload effects and truck travel times, on emissions, costs and production. The paper first looks at the background to the study, and then gives the optimal unit cost and unit emissions expressions. Queuing analysis is used to estimate changed emissions and costs resulting from altering fleet sizes. The paper compares the heterogeneous case with the homogeneous case.

The paper demonstrates that the usual way of running earthmoving operations, whether using homogeneous or heterogeneous equipment, namely that based on minimising unit costs, also has the least environmental impact, that is it also corresponds with minimum unit emissions. Conversely not running operations at minimum unit costs leads to unnecessary emissions.

The paper will be of interest to those designing and managing earthmoving and like operations, such as quarrying and surface mining, and also those concerned about environmental effects of construction.

\section{Background}

The background to the present study is given under the headings of: regulations and standards; measured field emissions; and modelling earthmoving.

\section{Regulations and standards}

Regulations and standards have developed with time in an attempt to measure and reduce emissions. The United States Environmental Protection Agency (EPA, 2008) and California Environmental Protection Agency Air Resources
Board (CARB, 2009) give the NONROAD and OFFROAD models for determining emissions of off-road equipment. These models can be used in the overall design and planning of earthmoving operations, and in particular in the selection of the appropriate combination of loading and hauling units. However, these models are not precise enough for specific work cycles, because they typically give emissions per year. Such models are very general, making use of average load factors, which are not job specific, to estimate the emissions.

Emissions from off-road vehicles presented in regulations and standards are usually quantified based on steadystate engine dynamometer tests (Frey et al., 2008a, 2008b), and hence may not be representative of actual emissions in the field. Research to date shows that exhaust emissions are very dependent on equipment type and the tasks that they are performing (Lewis, 2009; Pang, 2007). This points to the need for research data based on actual vehicle activities in order to study particular operations.

\section{Measured field emissions}

Frey et al. (2008b) and Hansen (2008) evaluate the effects of different blends of fuel on emissions from off-road vehicles. The results show that although the fuel use rate for different blends might be similar, emission rates from these fuels are different.

Measurements by Frey et al. (2008b) and Hansen (2008) show that actual equipment emissions could differ from emissions based on steady-state engine dynamometer tests as presented in EPA (2007). Gautum (2002) compares emissions of on-site diesel-powered off-road vehicles with that for engine dynamometer test beds. The results indicate that the steady-state test cycle does not suitably depict the emissions produced by off-road vehicles, and that exhaust emissions are very dependent 
on vehicle type. Thus, to have proper emissions data for modelling purposes, a range of vehicle types and models should be tested.

Lewis (2009) presents an approach that determines the emissions for specific work cycles of construction equipment. A portable emissions monitoring system was used to collect the fuel consumption and emissions data of seven types of equipment while they were working. The equipment measured comprised backhoes, bulldozers, excavators, motor graders, off-road trucks, track loaders and wheel loaders. Lewis divides engine load into 10 different modes and uses the average fuel consumption (modal fuel use) and emissions (modal emissions) in each mode to determine the emissions of different work cycles. Lewis' equations estimating fuel consumption in different engine modes can be used, along with the fraction of time equipment spends in different engine modes, to calculate emissions for a variety of engine powers and engine tiers.

The DCCEE (2011) approach calculates emissions based on field-measured fuel use. It multiplies the actual fuel use with a fuel-specific energy content and fuel-specific emission factors to give $\mathrm{CO}_{2}$ values, and $\mathrm{CO}_{2}$ equivalent $\left(\mathrm{CO}_{2}\right.$-e) values for $\mathrm{CO}_{4}$ (methane) and $\mathrm{N}_{2} \mathrm{O}$ (nitrous oxide). The sum of all these greenhouse gases gives total $\mathrm{CO}_{2}$-e emissions.

Both the approach of Lewis (2009) and DCCEE (2011) are used below, for comparison purposes.

\section{Modelling earthmoving}

Earthmoving operations may be looked at in a number of ways: linear programming (Stark and Nicholls, 1972; Stark and Mayer, 1983; Easa, 1987; Jayawardane and Harris, 1990); knowledgebased expert systems (Amirkhanian and Baker, 1992; Alkass and Harris,
1988); neural networks (Karshenas and Feng, 1992); and multiple regression (Chanda and Gardiner, 2010; Han et al, 2008). Queuing theory (Carmichael, 1987; Karshenas and Farid, 1988; Alkass et al., 2003), and discrete-event simulation (AbouRizk, 2010) are commonly used to estimate cycle times and production. All methods have advantages and disadvantages and personal preference and analysis intent will dictate which is used in any situation (Blackwell, 1999; Hardy, 2007; Chanda and Gardiner, 2010; Karshenas and Farid, 1988). Ahn et al. (2009) use discrete-event simulation to estimate different components of cycle times in a case study operation. The analysis in this paper uses finite source queuing theory, because of its analytical tractability, with modified distributions for service and backcycle times.

\section{Production, Costs and Emissions}

\section{Queuing theory}

For a homogeneous operation, single server, the average truck cycle time is given by (Carmichael, 1987),

$$
\frac{K}{\mu \eta}=\frac{1}{\mu}+\frac{1}{\lambda}+W_{q}
$$

where $1 / \mu$ is the average service time, $1 / \lambda$ is the average backcycle time, $W_{q}$ is the average waiting time at the server, $\eta$ is the server utilization (proportion of time the server is busy), and $K$ is the truck fleet size. Service may be at either the load or dump point. Service time, with respect to loading, is defined as the sum of the truck manoeuvre time prior to loading and load time, while the backcycle time is defined as the loaded haul time plus the dump time plus return time. Server utilisation, $\eta$, is determined based on an operation's servicing factor, $\rho=\lambda / \mu$.
Production is given by,

Production $=\mu \eta \mathrm{CAP} \tau$

where CAP is the capacity of a truck $(\mathrm{m} 3)$, and $\tau$ is the time period over which production is being measured.

Results from queuing theory are used in two forms below. The first assumes a deterministic operation, that is no variability in the equipment cycle time components; this is denoted ( $D / D$ / C) $/ K$. The second uses queuing results that mirror field observations closely, and this is an average of the (D/D/1)/K case and the exponential $(M / M / 1) / K$ case (Carmichael, 1989). D (constant) and $M$ (exponential) here refer to the distributions describing the service and backcycle times.

Gross and Ince (1981) consider time average and rate average approximations to convert a heterogeneous operation into an equivalent homogenous one. For time averaging,

$$
\begin{array}{r}
1 / \mu_{t}=\frac{\sum_{i=1}^{v} K_{i} / \mu_{i}}{\sum_{i=1}^{v} K_{i}} \\
1 / \lambda_{t}=\frac{\sum_{i=1}^{v} K_{i} / \lambda_{i}}{\sum_{i=1}^{v} K_{i}}
\end{array}
$$

For rate averaging,

$$
\begin{aligned}
& \mu_{r}=\frac{\sum_{i=1}^{v} K_{i} \mu_{i}}{\sum_{i=1}^{V} K_{i}} \\
& \lambda_{r}=\frac{\sum_{i=1}^{v} K_{i} \lambda_{i}}{\sum_{i=1}^{V} K_{i}}
\end{aligned}
$$

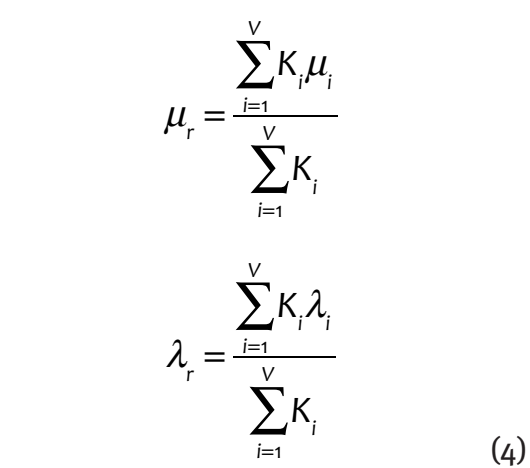

where $i=1,2, \ldots, V$ refers to truck type $\mathrm{i}$, and subscripts $\mathrm{t}$ and $\mathrm{r}$ refer to time 
averaging and rate averaging respectively.

These approximations result in two different servicing factors, $\rho_{\mathrm{t}}$ and $\rho_{\mathrm{r}}$. Gross and Ince (1981) suggest that a servicing factor between these values, with the choice being closer to the time average value, be selected as the servicing factor of the equivalent homogeneous operation. Although both time and rate averages are seen to be satisfactory for a restricted range of backcycle and service times, they can be a poor approximation for certain operating conditions (Carmichael, 1990, 1991); some modified results from Carmichael (1990), for the deterministic case, are presented below.

For the deterministic, homogeneous case, single server, the server utilization $\eta$ is given by (Carmichael, 1987)

$$
\eta=\min \left[\frac{K / \mu}{1 / \mu+1 / \lambda}, 1\right]
$$

For the deterministic, heterogeneous case, Carmichael (1990) presents solutions for when truck overtaking is not allowed. Equation (6) is used to estimate the server utilization when the queuing time is taken to account, while Equation (7) is used when the queuing time is not taken to account.

$$
\begin{gathered}
\eta=\min \left[\frac{\sum_{i=1}^{v} K_{i} / \mu_{i}}{\max \text { part cycle }}, 1\right] \\
\eta=\min \left[\sum_{\beta=1}^{K} \frac{1 / \mu_{\beta}}{1 / \mu_{\beta}+1 / \lambda_{\beta}+Q_{\beta}}, 1\right]
\end{gathered}
$$

Here 'max part cycle' is the largest $\left(1 / \mu_{i}+1 / \lambda_{i}\right)$ value of all the trucks. And,

$$
\begin{gathered}
Q_{\beta}=Q_{\beta}^{\prime}+\text { most negative } Q_{\gamma}^{\prime} \text { value } \\
\alpha, \beta=1,2, \ldots, K
\end{gathered}
$$

$$
\begin{gathered}
Q_{\beta}^{\prime}=\left[\sum_{\alpha \neq \beta} 1 / \mu_{\alpha}\right]-1 / \lambda_{\beta} \\
\alpha, \beta=1,2, \ldots, \mathrm{K}
\end{gathered}
$$

\section{Cost per production}

The cost per production of any single excavator operation is

Cost $/$ production $=\frac{C_{E}+K C_{T}}{\mu \eta C A P}$

where $C_{E}$ is the hourly operating cost of the excavator, and $C_{T}$ is the hourly operating cost of a truck (Carmichael, 1987, 1989).

\section{Emissions per production}

The total emissions per production of any single excavator operation can be obtained from,

Emissions $/$ production $=$

$$
\frac{\left(\eta \mathrm{N}_{\mathrm{E}}+(1-\eta) \mathrm{I}_{\mathrm{E}}\right)+\mathrm{K}\left(\eta_{\mathrm{T}} \mathrm{N}_{\mathrm{T}}+\left(1-\eta_{\mathrm{T}}\right) \mathrm{I}_{\mathrm{T}}\right)}{\mu \eta C A P}
$$

Here $\eta$ and $(1-\eta)$ are taken as the proportions of time that the excavator spends loading and idling respectively, and $\eta_{\mathrm{T}}$ and $\left(1-\eta_{\mathrm{T}}\right)$ are the proportions of time that the trucks spend travelling and idling (waiting and loading). These values can be observed in the field or estimated via, for example, simulation or queuing theory. $\mathrm{I}_{\mathrm{E}}, \mathrm{I}_{\mathrm{T}}, \mathrm{N}_{\mathrm{E}}$ and $\mathrm{N}_{\mathrm{T}}$ are idling and non-idling emissions of the excavator and truck, respectively; these can be estimated using the approaches of Lewis (2009) or DCCEE (2011).

With respect to the approach of Lewis (2009), although it is based on equipment work cycles, idling and non-idling emissions can be estimated with manipulation of the data. Lewis et al. (2012) present idle and non-idle times of equipment, as observed in the field, in conjunction with the approach of Lewis (2009). This paper uses the times in Lewis et al. (2012) to redistribute the fractions of time spent in different en- gine modes for idling and non-idling activities, and to estimate idling and non-idling fuel use and, consequently, emissions.

\section{Case Study}

Site data were collected on cut-and-fill work on a highway construction site. The operation employed a fleet of 4 trucks - two articulated trucks (referred to as $\mathrm{T} 16$ below), two rigid body trucks (referred to as T26 below), and one excavator. The equipment characteristics are summarised in Table 1.

\begin{tabular}{|l|c|c|c|c|} 
& $\begin{array}{c}\text { Load } \\
\left(\mathrm{m}^{3}\right)\end{array}$ & $\begin{array}{c}\text { Engine } \\
\text { power (HP) }\end{array}$ & $\begin{array}{c}\text { Engine } \\
\text { tier }\end{array}$ & $\begin{array}{c}\text { Cost } \\
\text { ratio }\end{array}$ \\
\hline Truck T16 & 16 & 469 & 3 & 0.44 \\
\hline Truck T26 & 26 & 739 & 3 & 0.53 \\
\hline Excavator & & 689 & 3 & 1 \\
\hline
\end{tabular}

Table 1. Equipment characteristics; costs $(\$ / h)$ relative to excavator cost.

Field time measurements were carried out over many truck cycles. Table 2 gives the average cycle component times.

\begin{tabular}{|l|c|c|}
\hline & $\begin{array}{c}\text { All trucks } \\
\text { combined }\end{array}$ & T2 6 \\
\hline Queue time & 30.8 & 57.6 \\
\hline $\begin{array}{l}\text { Manoeuvre time at } \\
\text { excavator }\end{array}$ & 37.1 & 35.4 \\
\hline Load time & 73.3 & 50.8 \\
\hline Backcycle time $(1 / \lambda)$ & 539.3 & 565.8 \\
\hline Service time $(1 / \mu)$ & 110.4 & 86.2 \\
\hline Servicing factor $(\lambda / \mu)$ & 0.205 & 0.152 \\
\hline
\end{tabular}

Table 2. Field observed average cycle component times (sec).

Performing time averaging and rate averaging, as in Equations (3) and (4),

$$
\begin{array}{ll}
1 / \mu_{t}=109.6 & 1 / \lambda_{t}=541.1 \\
1 / \mu_{r}=104.6 & 1 / \lambda_{r}=540.0
\end{array}
$$

This gives the servicing factors,

$$
\rho_{t}=0.203 \quad \rho_{r}=0.194
$$

Gross and Ince (1981) suggest using a servicing factor lying between these 
values, but closer to the time average value. For the present case, the servicing factor from time averaging is essentially the same as that observed for all trucks combined, because of the same number of each type of truck being used, and no overtaking occurring.

The server utilizations given by Equations (5), (6) and (7) respectively are,

$$
\begin{aligned}
& \eta=\min \left[\frac{4 \times 110.4}{110.4+539.3}, 1\right]=0.68 \\
& \eta=\min \left[\frac{2 \times 133.1+2 \times 86.2}{652}, 1\right]=0.67 \\
& \eta=\min \left[2 \times \frac{133.1}{652}+2 \times \frac{86.2}{652}, 1\right]=0.67
\end{aligned}
$$

The server utilizations are essentially the same because of the same number of each type of truck being used, and because the backcycle times and 'part cycle' times for the trucks are similar. These deterministic server utilizations provide an upper bound on the operation production.

\section{Analysis and Discussion}

\section{Unit costs and unit emissions}

The influence of varying the truck fleet size on unit costs for three scenarios, all using Table (2) values - heterogeneous, homogenous T16 only, and homogeneous T26 only - is examined in Figures 1 and 2. Queuing analysis averaging the $(D / D / 1) / K$ and $(M / M / 1) / K$ cases is used. (Figure 1.)

Similar results are obtained for unit emissions in Figure 2, where $\mathrm{CO}_{2}$-e per production is calculated using the DCCEE (2011) approach. It is seen that the optimum fleet sizes in terms of unit emissions are the same as those for the optimum fleet sizes in terms of unit costs, for both the homogenous and heterogeneous cases. (Figure 2.)

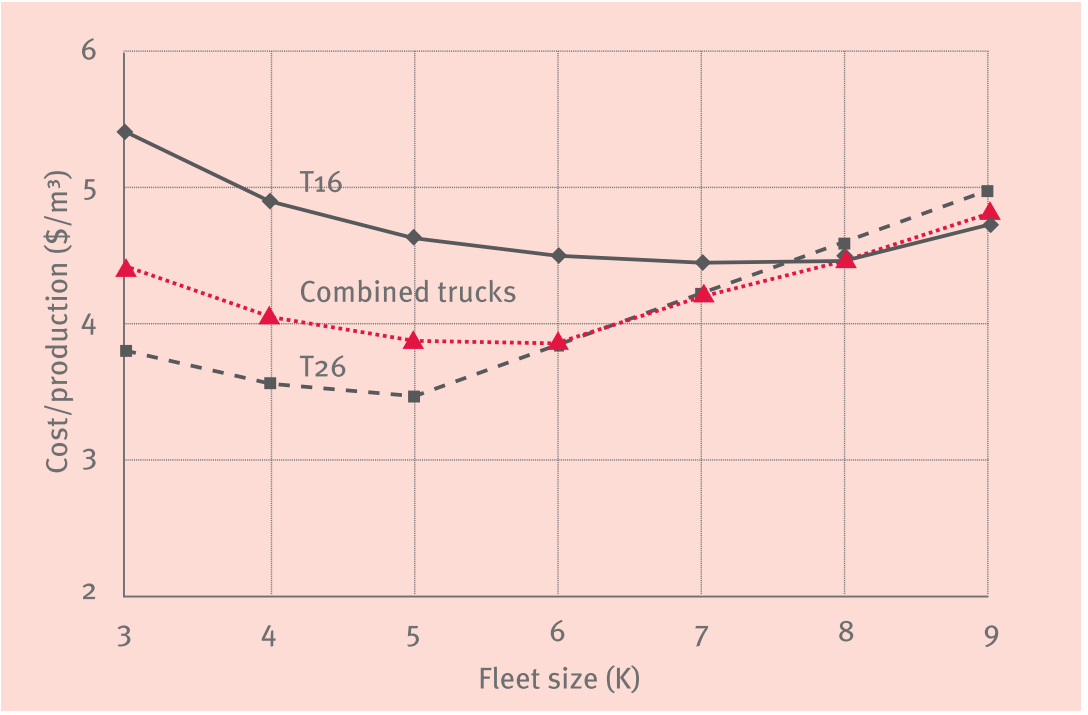

Figure 1. Cost/production versus fleet size for different fleet configurations.
For the particular data, it is seen that the T26 trucks result in lower unit costs, yet higher unit emissions, compared with $T_{16}$ trucks. This results because of the large difference between the cost ratio and the fuel use ratio for the two truck types. The ratio of hourly operating costs of trucks T26 to T16 is approximately 1.0, while the ratio of hourly fuel use is approximately 2.0 .

The influence of different operation parameters, on this result of coincident optima for unit costs and unit emissions, can be explored. The following looks at the influence of varying the payload (and hence service time and volume moved per truck) and truck travel times (and hence backcycle time) on unit costs and unit emissions. The analyses show that the coincident result remains on changing operation parameters.

\section{Payload}

The effect of underloading trucks is examined through varying the number of

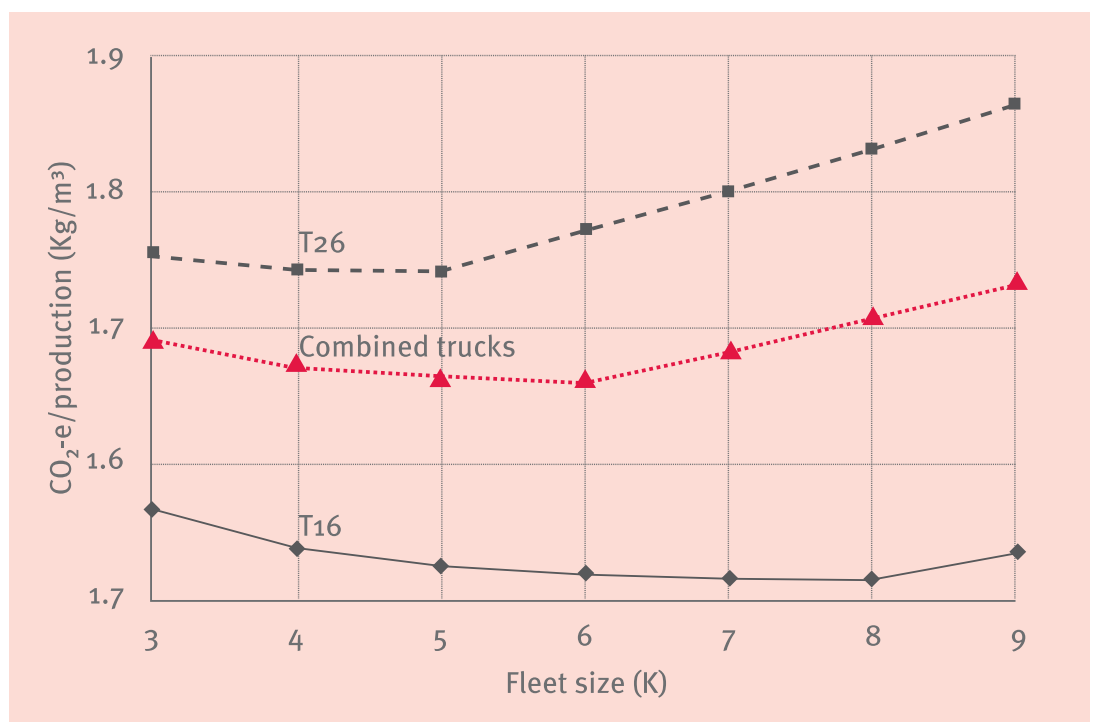

Figure 2. $\mathrm{CO}_{2}-\mathrm{e} /$ production versus fleet size for different fleet configurations. 
excavator buckets loaded less than the usual 5 buckets. Cost per production and emissions per production values for the homogenous case (truck T26 only) are plotted in Figure 3 for varying numbers of buckets per truck. Loading with less buckets translates to lower serving times and lower volume moved per truck; truck fuel use, with associated cost, decreases with lower engine loads.

The results show that the optimum fleet size is the same for both unit cost and unit emissions, regardless of the payload. It can also be seen that the optimum fleet size, cost per production and emissions per production increase as the payload decreases. This is because of the reduced volume moved per truck. (Figure 3)

Similar results occur for $\mathrm{T}_{16}$ trucks (Figure 4) when the number of buckets loaded is reduced below the usual 4 buckets.

\section{Haul and return distances}

Longer haul and return distances translate into larger backcycle times. Optimum fleet sizes are plotted in Figure 5 for varying backcycle times. The optimum fleet sizes have some overlapping. As well, because of the flatness of the unit costs and unit emissions plots, and the plots only being defined at integer $\mathrm{K}$ vales, the ends of the bars in Figure 5 may not be distinctly defined. (Figure 5)

The information in Figure 5 may be alternatively presented as in Figure 6 . The length of the bars in Figure 6 reflects the differing carrying capacities of the trucks and the number of each truck type necessary to produce the same production - the larger the truck the longer the bar. (Figure 6)

The difference between the optimum $\mathrm{CO}_{2}$-e/production and optimum $\mathrm{CO}_{2} /$ production values is due to the two dif-

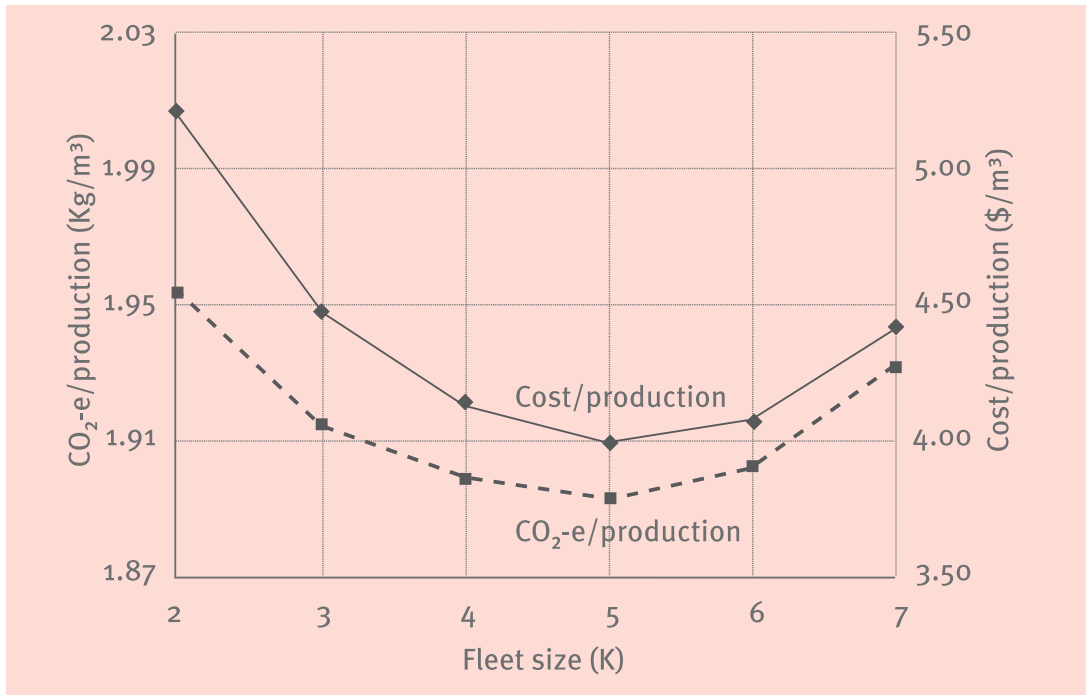

(a) 4 buckets/truck.

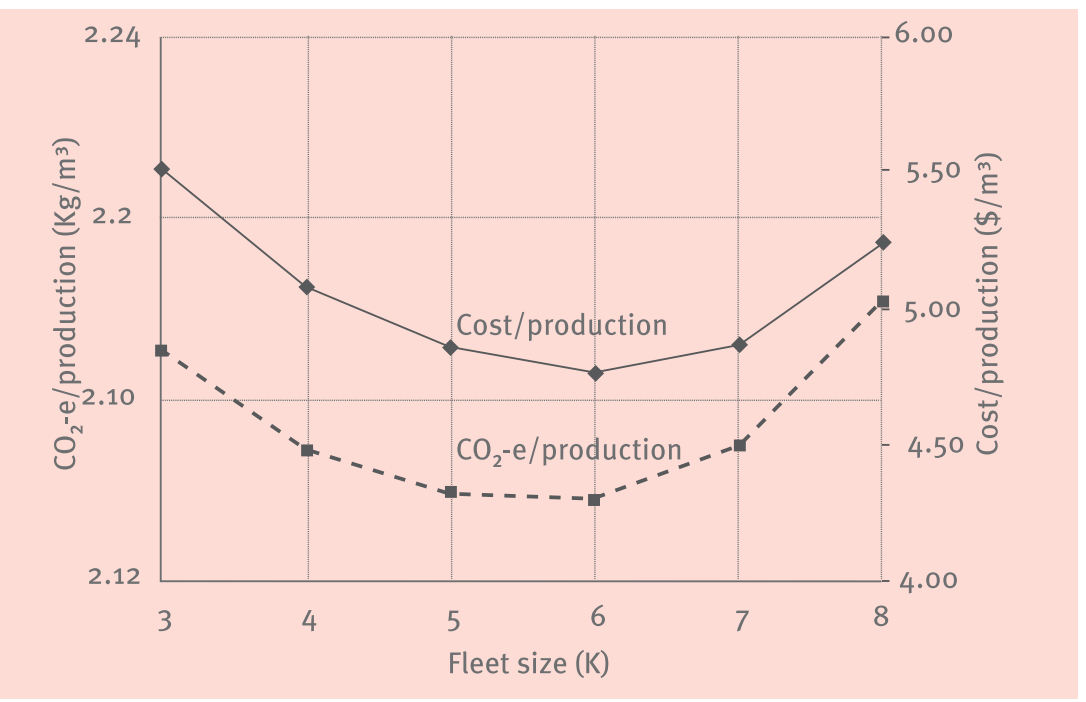

(b) 3 buckets/truck.

Figure 3. The effects of reduced number of excavator buckets loaded (T26 trucks).

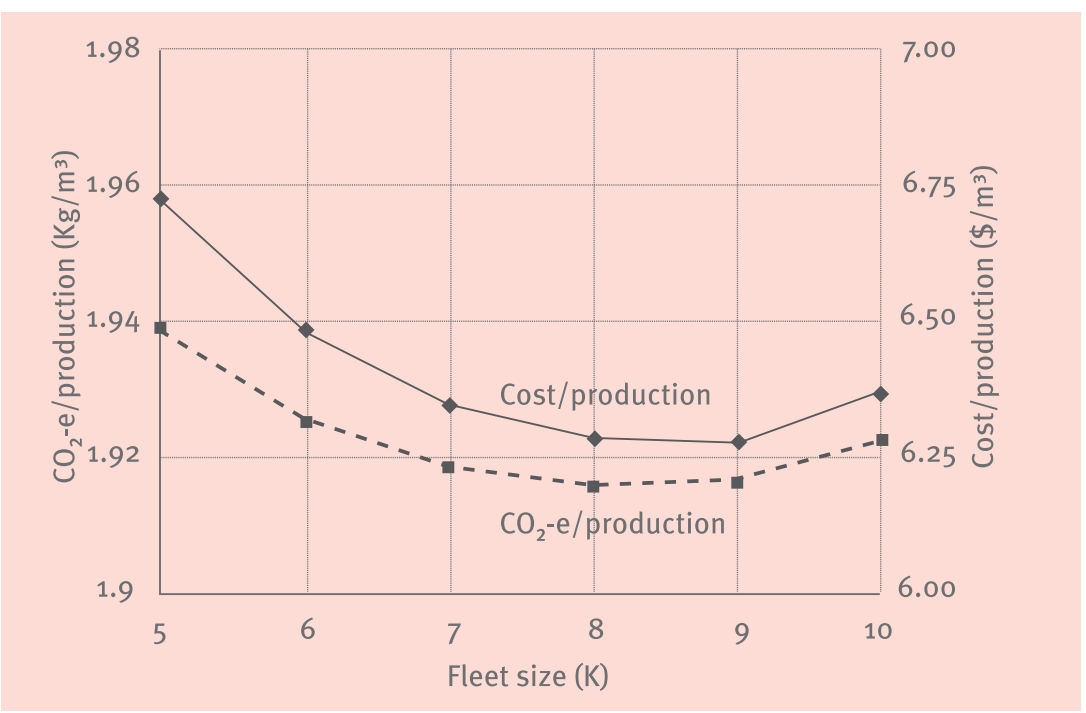

Figure 4. The effects of reduced number of excavator buckets loaded (T16 trucks; 3 buckets/truck). 


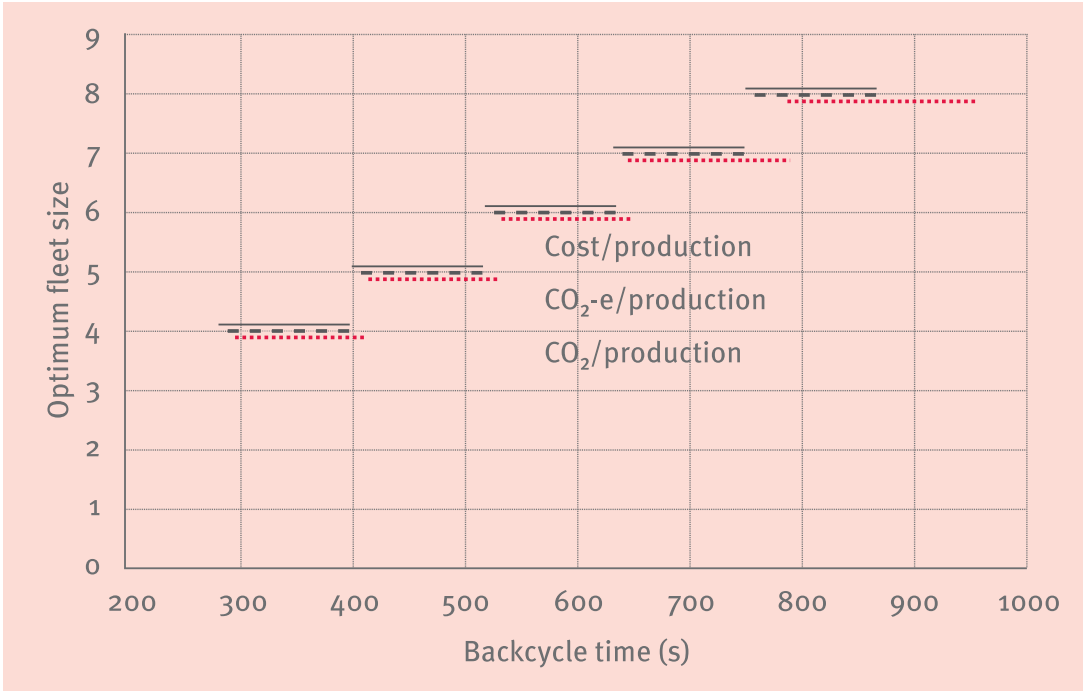

(a) Heterogeneous operation (combined T16 and T26 trucks).

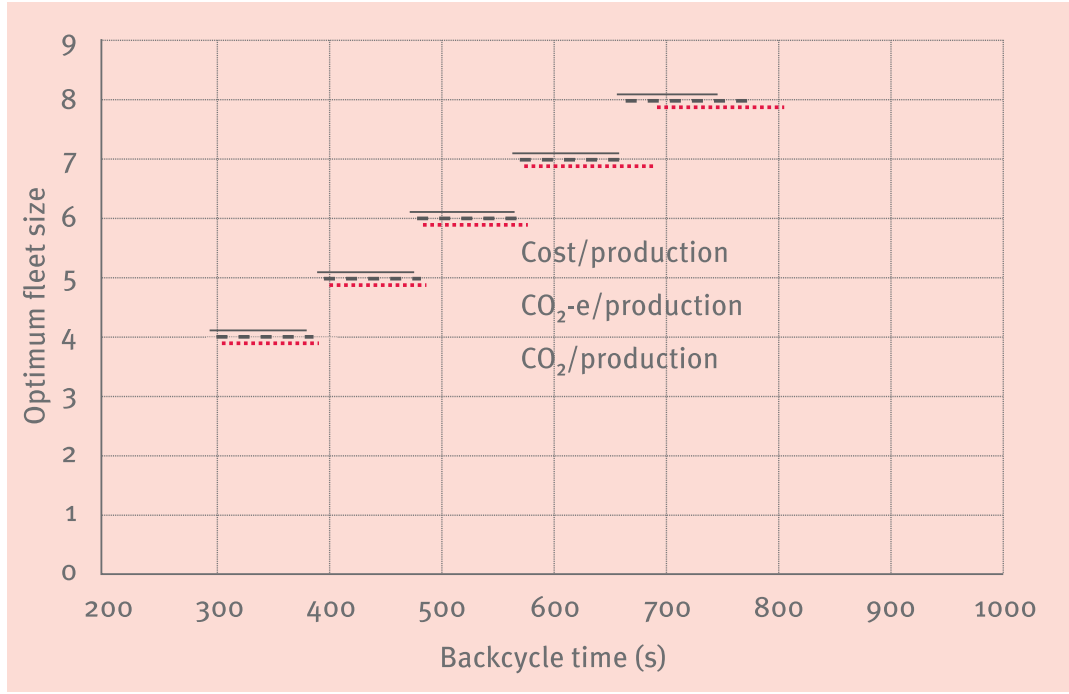

(b) Truck T16 only.

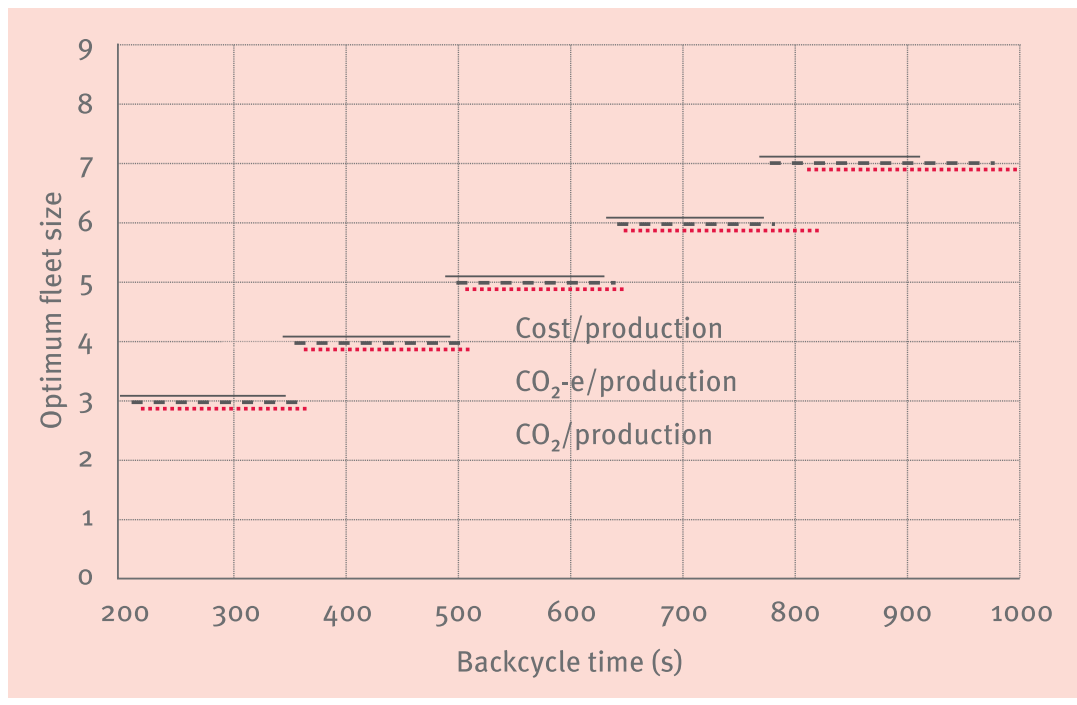

(c) Truck T26 only.

Figure 5. Optimum fleet size versus backcycle time. ferent methods used to obtain $\mathrm{CO}_{2}$-e and $\mathrm{CO}_{2}$, namely DCCEE (2011) and Lewis (2009) respectively. The approach of Lewis (2009) could be expected to underestimate non-idling emissions of large equipment: the original modelling involved smaller equipment (Lewis 2009, p. 61); and the work cycles observed by Lewis included long idle times and short backcycle times, and with short haul distances, trucks move with low speeds and, as a result, low engine loads (Frey et al., 2010). Thus, the overall average engine load presented in Lewis (2009) is not representative of all truck work cycles. Accordingly, both the approaches of Lewis (2009) and DCCEE (2011) are used in this paper, for comparison purposes, to estimate idling and non-idling emissions of equipment.

Idle time in the excavator can be used to increase individual truck production, in that an idle excavator is available to 'serve' a truck on its arrival, and vice versa. For a fleet of trucks, there is a trade-off between truck idle time, excavator idle time and production. Increased total idle time for all equipment leads to increased total fuel use and consequently increased emissions (Lewis et al., 2012; Ferry et al., 2008), and increased cost. Hidden costs include additional engine maintenance and reduced engine life (New York Planning Federation, 2006). Therefore, some knowledge of equipment idle time is useful for operation management purposes. Idle and non-idle times of three scenarios (fully heterogeneous, homogenous T16 only, and homogeneous T26 only) are plotted for the excavator and trucks in Figures 7 and 8. The upper curve in Figure 7, for example, shows non-idle time of the excavator versus the fleet size while loading a homogeneous fleet of T26 trucks.

For small but increasing fleet sizes, the slopes in the idling and non-idling plots are constant, but the slope changes at 
approximately the match point of the operation. The change points for trucks T26, combined trucks and trucks T16 are 5, 6 and 8, respectively, which are the optimum fleet sizes derived above. The changes in the slopes are different for the excavator and for the trucks. This implies that an increase in the fleet size has a different influence on idle and non-idle times of the trucks and the excavator. However, idling and non-idling emissions of a truck and an excavator differ. Therefore, it is difficult to establish in general terms how varying the fleet size changes the total emissions. Nevertheless, the analyses in this paper show that the match point of an operation is very close to the optimum in terms of unit costs and unit emissions.

\section{Conclusion}

The paper examined the influence of varying operation parameters on earthmoving emissions, costs and production. Field measured data in conjunction with queuing theory were used to determine unit costs and unit emissions for varying fleet sizes. The approaches of DCCEE (2011) and Lewis (2009) were used to quantify emissions. The paper demonstrated over a range of values of operation parameters that the optimum fleet size in terms of minimum unit cost coincides with that for minimum unit emissions. The result was shown to be true for both heterogeneous and homogeneous operations.

Analyses were performed to evaluate the effects of changing operation parameters such as payload and travel times. It was demonstrated that the optimum fleet size, and also unit costs and unit emissions increase as the payload decreases. Other studies carried out by the authors on different excavators support the conclusions. The different analyses confirm that the result of the optimum fleet size in terms of unit costs and unit emissions coinciding is robust to changing operation parameters.

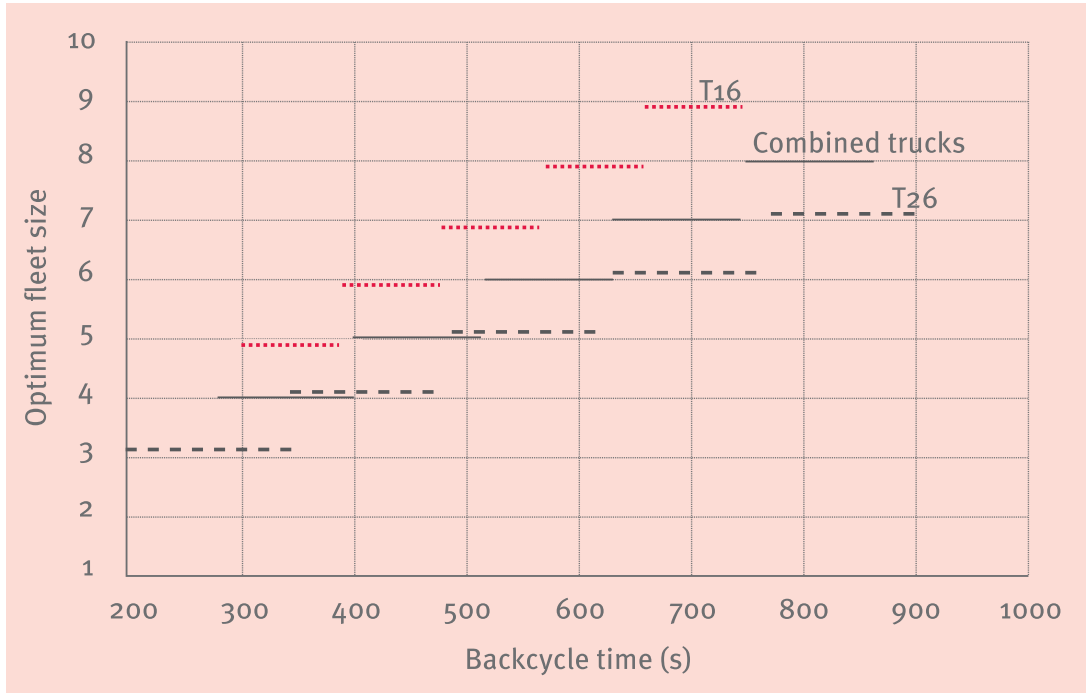

(a) Optimum cost/production.

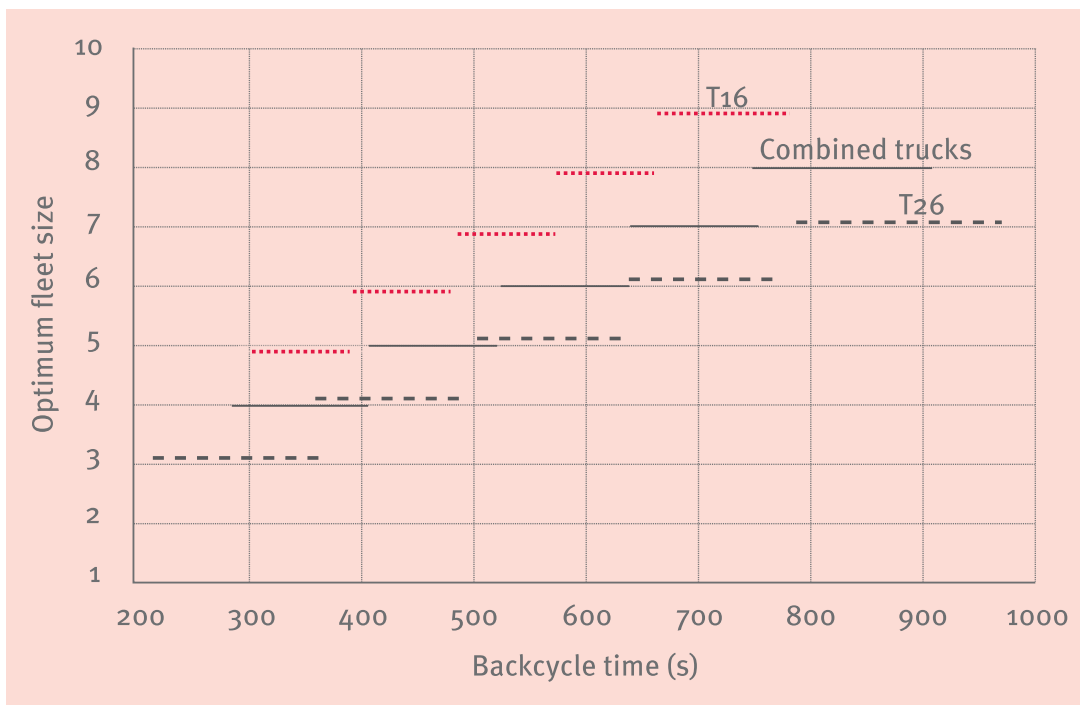

(b) Optimum $\mathrm{CO}_{2}$-e/production.

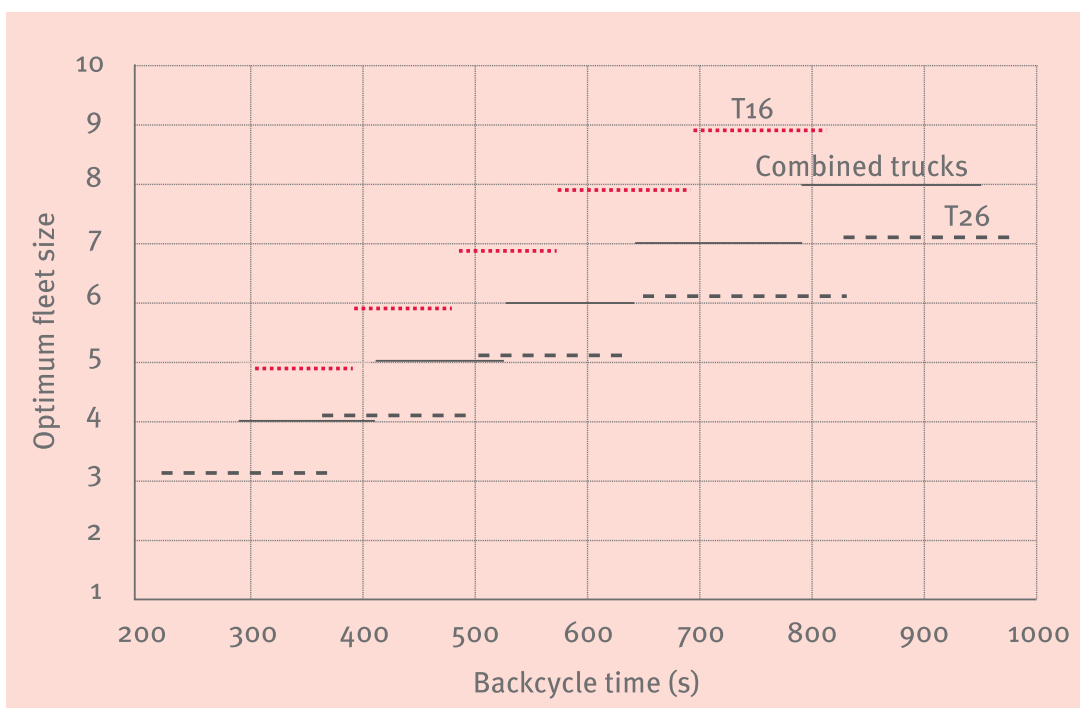

(c) Optimum $\mathrm{CO}_{2} /$ production.

Figure 6. Optimum fleet sizes. 


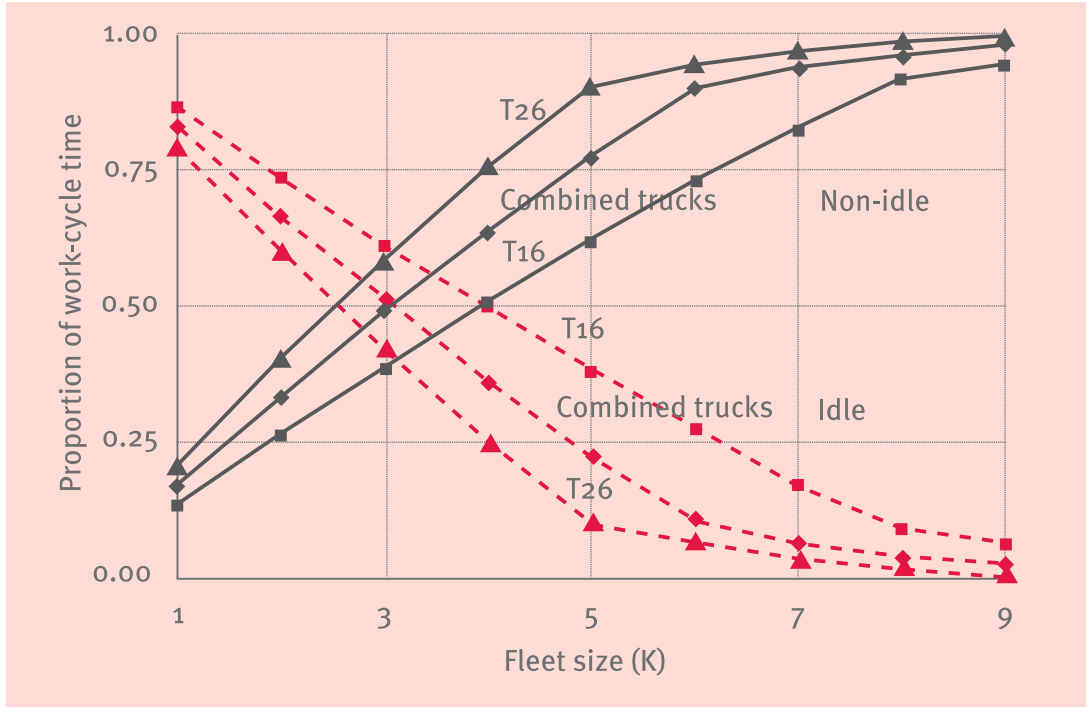

Figure 7. Idle and non-idle times of the excavator.

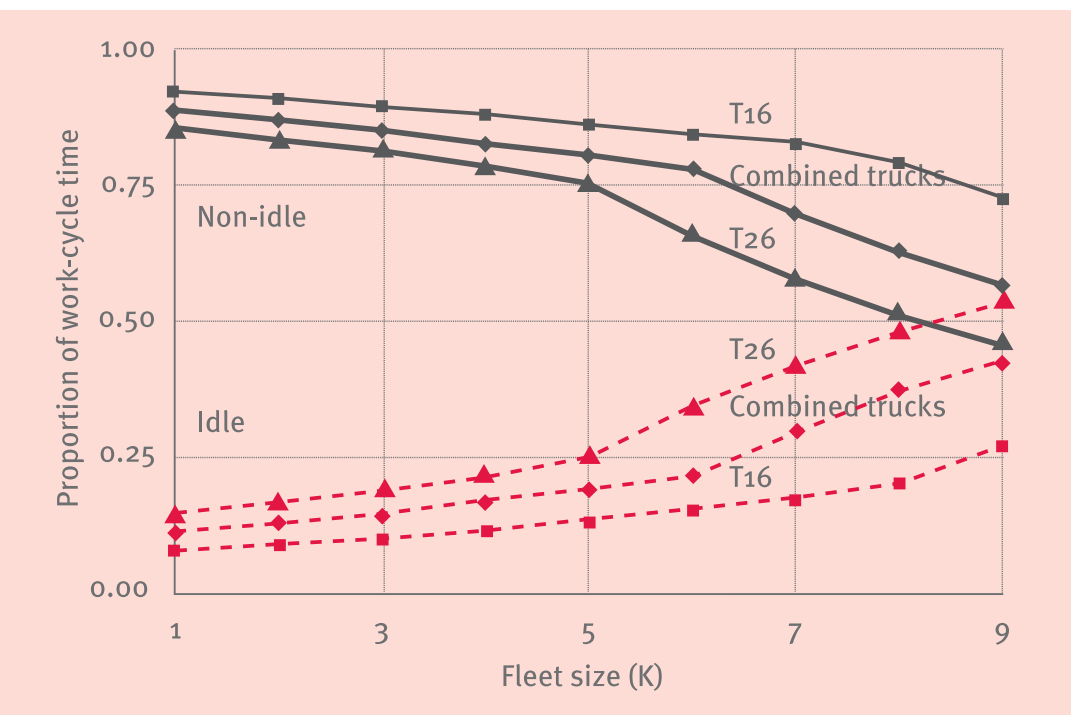

Figure 8. Idle and non-idle times of the trucks.

Comparing calculated optimum fleet sizes with operation match points highlighted the importance of the proportion of idle to non-idle times of the equipment.

The paper concludes that the traditional way of undertaking earthmoving operations, namely configuring to give minimum unit costs, will also result in minimum unit emissions. And that configuring differently to that will lead to unnecessary emissions.

Based on the underlying analysis, the coincidence of the optimum unit costs
M. (2003), A Computer Model for Selecting Equipment for Earthmoving Operations using Queuing Theory, Proceedings of the CIB W78's 2oth International Conference on Information Technology for Construction Construction IT Bridging the Distance, Auckland, New Zealand, 23-25 April, pp. 1-7. 〈http://itc.scix.net/cgi-bin/works/ Show?w78-2003-1> [viewed 25 April 2012].

Alkass, S. and Harris, F. (1989), Expert System for Earthmoving Equipment Selection in Road Construction, Journal of Construction Engineering and Management., ASCE, Vol. 114, No. 3, pp. 426-440.

Amirkhanian, S. N. and Baker, N. J., (1992), Earth-Moving Operations, Journal of Construction Engineering and Management, ASCE, Vol. 118, No. 2, pp. 318-331.

Blackwell, G. H. (1999), Estimation of Large Open Pit Haulage Truck Requirements, CIM Bulletin, Vol. 92, No. 1028, pp. 143-149.

Burt, C. N. and Caccetta, L. (2007), Match Factor for Heterogeneous Truck and Loader Fleets, International Journal of Mining, Reclamation and Environment, Vol. 21, No. 4, pp. 262-270.

CARB (2009), Off-Road Emissions Inventory Program, Version 2009; California Air Resources Board, Sacramento. < http:// www.arb.ca.gov/msei/offroad/offroad. $\mathrm{htm}>$ [viewed 4 October 2009].

Carmichael, D. G. (1987), Engineering Queues in Construction and Mining, Ellis Horwood Ltd, Chichester.

Carmichael, D. G. (1989), Production Tables for Earthmoving, Quarrying and Opencut Mining Operations, pp. 275-284, in Applied Construction Management, Unisearch Ltd Publishers, Sydney, ISBN $090979619 \mathrm{X}$.

Carmichael, D. G. (1990), Heterogeneity in Deterministic Finite Source Queues, Civil Engineering Systems, Vol. 7, No. 1, pp. 11-19.

Carmichael, D. G. (1991), Approximations for heterogeneous finite source queues, Civil Engineering Systems, Vol. 8, No. 3, pp. 174-178

Carmichael, D. G., Williams E. H. and Kaboli A. S. (2012), Minimum Operational Emissions in Earthmoving, 
ASCE Construction Research Congress, 21-23 May, Purdue University, USA.

Chanda, E. K. and Gardiner, S. (2010), A Comparative Study of Truck Cycle Time Prediction Methods in Open-pit Mining, Engineering, Construction and Architectural Management, Vol. 17, No. 5, pp. 446-460.

DCCEE (2011), National Greenhouse Accounts Factors, Department of Climate Change and Energy Efficiency, Canberra.

Easa, M. S. (1987), Earthwork Allocations with Nonconstant Unit Cost. Journal of Construction Engineering and Management, ASCE, Vol. 113, No. 1, pp. 34-50.

EPA (2005), Clean Construction USA, U.S. Environmental Protection Agency, 〈http://www.epa.gov/cleandiesel/ documents/420fo5032.pdf> [viewed 25 October 2011].

EPA (2007), Diesel Retrofit Technology Verification: Verified Technologies List, U.S. Environmental Protection Agency, 〈http://epa.gov/cleandiesel/ verification/verif-list.htm> [viewed 7 October 2011].

EPA (2008), NONROAD Model (Nonroad Engines, Equipment, and Vehicles), U.S. Environmental Protection Agency, U.S.A, 〈http://www.epa.gov/OMS/nonrdmdl. htm>, [viewed 1 October 2011].

Frey, H. C., Kim, K., Rasdorf, W., Pang, S.-H. and Lewis, P. (2008a), Characterization of Real-world Activity, Fuel Use, and Emissions for Selected Motor Graders Fueled with Petroleum Diesel and B2o Biodiesel. Journal of the Air and Waste Management Association, Vol. 58, No. 10, pp. 1274-1287.

Frey, H. C., Rasdorf, W., Kim, K., Pang, S. and Lewis, P. (2008b), Comparison of Real-World Emissions of B20 Biodiesel Versus Petroleum Diesel for Selected Nonroad Vehicles and Engine Tiers, Transportation Research Record: Journal of the Transportation Research Board, Vol. 2058, No. 5, pp. 33-42.

Frey, H. C., Rasdorf, W. and Lewis, P. (2010), Comprehensive Field Study of
Fuel Use and Emissions of Nonroad Diesel Construction Equipment, in Transportation Research Record: Journal of the Transportation Board, No. 2158, Transportation Research Board of the National Academies, Washington, D.C., pp. 69-76.

Gross, D. and Ince, J. F (1981), The Machine Repair Problem with Heterogeneous Populations, Operations Research, Vol. 29, No. 3, pp. 532-549.

Gautum, M. (2002), Testing for Exhaust Emissions for Diesel Off-road Engines, prepared for California Air Resources Board. Department of Mechanical and Aerospace Engineering, West Virginia University. Morgantown, West Virginia. Han, S., Hong, T. and Lee, S. (2008), Production Prediction of Conventional and Global Positioning System-based Earthmoving Systems using Simulation and Multiple Regression Analysis, Canadian Journal of Civil Engineering, Vol. 35, No. 6, pp.574-587.

Hardy, R. H. (2007), Selection Criteria for Loading and Hauling Equipment - Open Pit Mining Applications, PhD thesis, Curtin University of Technology, Perth, Australia.

Hansen, T. (2008), In-use Evaluation of Emissions from Non-road Diesel Equipment Using Biodiesel Fuel, paper prepared for The NY State Energy Research and Development Authority, Albany NY, «http://www.nyserda.org/ publications> [viewed 5 October 2011]. Jayawardane, A. K. W. and Harris, F. C. (1990), Further Development of Integer Programming Applied to Earthmoving Operations, Journal of Construction Engineering and Management, ASCE, Vol. 116, No. 1, pp. 18-34

Karshenas, S., and Farid, F. (1988), Multiloader-truck Fleet Selection for Earthmoving, Transportation Research Record, Vol. 1186, pp. 51-65.

Karshenas, S., and Feng, X. (1992), Application of Neural Networks in Earthmoving Equipment Production Estimating, Proc., 8th Conference in
Computing in Civil Engineering and Geographic Information Systems, ASCE, New York, N.Y., pp. 841-847.

Lewis, M. (2009), Estimating Fuel Use and Emission Rates of Nonroad Diesel Construction Equipment Performing Representative Duty Cycles, PhD thesis, North Carolina State University, <http:// gradworks.umi.com/33/57/3357743. html〉[viewed 25 March 2010].

Lewis, P., Leming, M., and Rasdorf, W. (2012), Impact of Engine Idling on Fuel Use and $\mathrm{CO}_{2}$ Emissions of Nonroad Diesel Construction Equipment, Journal of Management in Engineering, Vol. 28, No. 1, pp. 31-38.

Morgan, W. and Peterson, L. (1968), Determining Shovel-Truck Productivity, Mining Engineering, Vol. 20, No. 12, pp. 76-80.

Pang, S.-H. (2007), Life Cycle Inventory Incorporating Fuel Cycle and RealWorld In-Use Measurement Data for Construction Equipment and Vehicles, PhD Thesis in Civil Engineering, North Carolina State University, North Carolina.

Rekapalli, P. V. (2008), Discrete-event Simulation Based Virtual Reality Environments for Construction Operations. PhD thesis, Purdue University, West Lafayette, IN.

Stark, R., and Mayer, R. (1983), Quantitative Construction Management: Uses of Linear Optimization, John Wiley and Sons, New York, N.Y.

Stark, R., and Nicholls, R. (1972), Mathematical Foundations for Design: Civil Engineering Systems, McGraw-Hill Publishing Co., Inc., New York, N.Y. New York Planning Federation (2006), A Municipal Official's Guide to Diesel Idling Reduction in New York State, Technical Rep. with Funding from New York State Energy Research and Development Authority and U.S. Environmental Protection Agency's Smartway Transport Partnership, New York. 